\title{
Online Food Marketing in the Livestream Environment: What Is the Role of Censorship?
}

\author{
Caitlyn G. Edwards ${ }^{a}$ Catherine Claire Pollack ${ }^{b, c}$ Emma J. Boyland ${ }^{d}$ \\ Rebecca K. Evans $^{d}$ Diane Gilbert-Diamond ${ }^{b}$, e Travis D. Masterson ${ }^{a}$ \\ aDepartment of Nutritional Sciences, State College, The Pennsylvania State University, University Park, PA, USA; \\ ${ }^{b}$ Department of Epidemiology, Geisel School of Medicine, Dartmouth College, Hanover, NH, USA; 'Department \\ of Biomedical Data Science, Geisel School of Medicine at Dartmouth College, Hanover, NH, USA; dDepartment \\ of Psychology, University of Liverpool, Liverpool, UK; ' Norris Cotton Cancer Center, Geisel School of Medicine, \\ Dartmouth College, Hanover, NH, USA
}

Children and adults are spending ever increasing amounts of time online $[1,2]$. In recent years, companies such as Amazon, Microsoft, and Google have invested heavily in a new form of online social media referred to as "livestreaming." Livestreaming platforms, such as the Amazon-owned platform Twitch, are hybrid social media platforms that enable users to broadcast live audio and visual content to viewers. Viewers can also interact with streamers in real time through a live interactive chat room. Aside from being able to garner a large viewership [3], livestreaming provides unique marketing opportunities. The instantaneous nature of communication within the livestream environment allows for amplification of typical marketing techniques such as product placement and endorsement through direct interaction between marketers and potential consumers. For example, not only can a company place a product in the stream of content, ensuring viewer exposure to the product, they can also have the streamer interact with the product, endorse the product, and engage users about the product. This set

karger@karger.com

(c) 2020 S. Karger AG, Basel

www.karger.com/anm

Karger! of interactions can provide a seemingly "authentic" experience for the potential consumer. Additionally, companies can directly and instantaneously interact with viewers by initiating advertisements, real-time games, and promotional giveaways that further generate conversation within the chat rooms involved around their brands and products.

Since its arrival in 2011, Twitch has become the largest livestreaming platform, reportedly broadcasting 355 billion minutes of content to an average of 15 million unique daily visitors in 2017 [4]. In parallel with a growing stream of viewership (91\% of whom are estimated to be male, and $60 \%$ estimated to be between the ages of 18 and 34), Twitch's marketing revenue, including from the food and beverage industry, is on a rapid upward trajectory [3]. While the largest category of marketed food and beverage items on Twitch are energy drinks, there has been a rise in other products including fat- and sugar-laden products such as snack foods and candy [5]. As an example, in March of 2019, the Hershey Co. collaborated with Twitch 


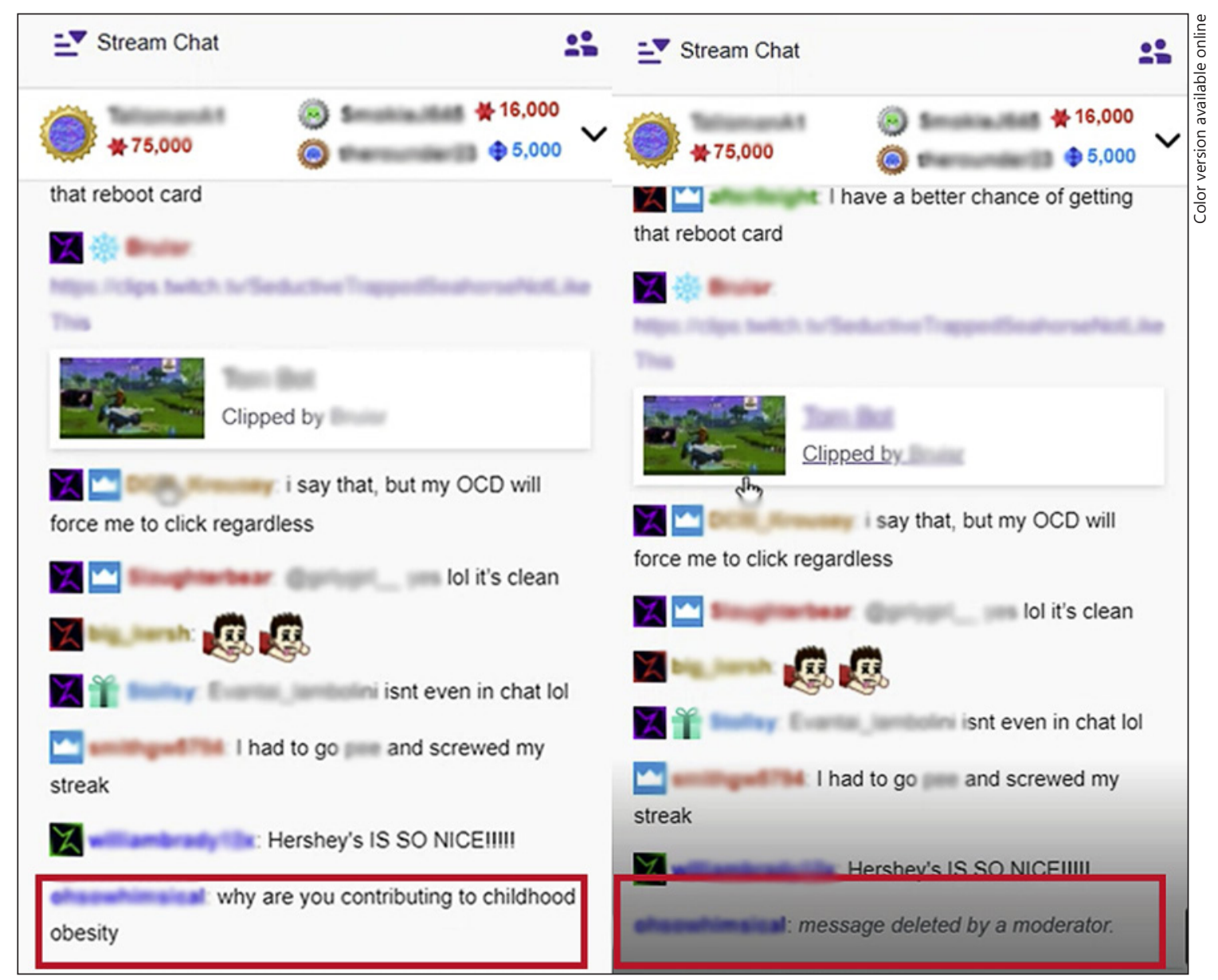

Fig. 1. Screenshots of a livestream chat box during a Hershey's sponsored and Twitch-hosted livestream event. In the first column you can see the comment "why are you contributing to childhood obesity," and in the second column you can see the automated text "message deleted by a moderator."

and a number of top livestreamers to promote its Hershey's and Reese's brands. Data previously collected by our group showed an unprecedented spike (e.g., a 2,388\% increase for Reese's) in marketing exposure for these brands during the 2-month long campaign [5].

Currently, the marketing environment on Twitch is more or less unregulated. Recently US federal laws have required that, at a minimum, the streamer should explicitly disclose whether a segment or product is part of a marketing campaign through the use of tags such as "\#ad" or "\#sponsored" in the stream's title [6]. Interestingly, the disclosure that content is paid for has been shown to actually cause increases in consumption of marketed products rather than deter viewers by highlighting the persuasive intent [7]. Of note, in comparison to other social media sites, Twitch marketing campaigns happen live and in real time. This is likely to reinforce an unscripted and authentic sentiment to the marketing campaign. For example, the streamer is likely presumed to be sharing their original thoughts on the product and responding to viewers naturally without external prompting. However, these situations may be far less genuine than they appear as streamers are aware that the marketing agencies have invested in their content, and there is no transparency over the control that these companies exert over the content and userstreamer interactions during sponsored segments.

For example, during the aforementioned marketing campaign for Hershey's chocolate a user asked the streamer through the live public chat room, "why are you contributing to childhood obesity" (shown in Fig. 1). The message was promptly deleted by the chat moderator. It is unclear why the moderator chose to censor this com- 
ment and if the sponsorship with the Hershey Co. played a role in the decision. Regardless, the Hershey Co. avoided a potentially distracting negative interaction through such censorship. We do note that critical comments such as the one discussed here are not unique to Twitch and are routinely experienced by companies across a variety of social media platforms [8]. Traditionally marketers have taken several approaches towards extinguishing public negativity, including but not limited to delaying a response, immediately responding, partnering with the offending voice, pursuing legal action, and/or censorship [8]. Nestlé, in a now infamous case study of marketing gone wrong, chose censorship in the online space in early 2010. In its Facebook group, Nestlé notified users that messages alluding to an ongoing awareness campaign from environmental activists around its dislike of Nestlé's palm oil supplier would be deleted. This appears to have backfired, and ignited public awareness and response leading to a surge of nearly 90,000 vocal critics on their Facebook page. Nestlé subsequently announced its search for a new marketing agency to handle its online image [9].

In both of these food maketing examples, the decision to censor was made towards content that was deemed detrimental to the brand's image. Two of the major differences between the Twitch and the Facebook example are the speed and visibility of the censorship. Twitch chat boxes move at a brisk pace and moderators can censor comments immediately leaving little time for other viewers to read the comments and understand that an opinion has been censored. With the ability for such rapid censorship, this public chat space is no longer a space for bidirectional interaction but can instead become an advertiser dominated environment. We do acknowledge that in some cases, deleting a user comment on Twitch may be necessary for the protection of users. However, the comment in question did not violate Twitch's user guidelines or the specific community rules set forth by the streamer [10]. This is alarming and potentially a limitation of free speech, a concept in which brands are heavily dependent on in their own lobbying against advertising restrictions [11]. We note that Twitch considers the chat to be "an essential component of the broadcast experience" and that Twitch streamers are allowed to "exercise control over the environment" [10]. However, in this case, the exchange of money between the streamer and the company essentially provides marketers leverage to control the chat instead of allowing natural discussion to happen. The precedent established by this example is worrisome, particularly for younger consumers who may not be aware of such intricacies within the digital marketing environment that they are participating in.

Arguably a license for censorship is warranted when moderating a chat of thousands of people, but the present lack of guidelines for the use of censorship to stifle legitimate concerns of viewers in the endorsement of products in the new age of livestream media benefits the advertiser over the user and contributes to the growing power or strength of influence of brands over viewers [12]. As livestreaming grows in popularity both within and outside of the Twitch platform, the imbalance and lack of transparency of control that marketing groups are allowed to have compared to the voice viewers and consumers are allowed to express during marketing campaigns needs to be discussed. The present lack of regulations for advertising in the livestream environment enables brands to inappropriately establish the tone, expectation, and norms around their products based on their profit-driven agenda. To move responsibly forward in an increasingly digital age, regulations must be established on the role brands, particularly those related to consumer health, may play within the livestreaming environment.

\section{Conflict of Interest Statement}

The authors have no conflicts of interest to declare.

\section{Funding Sources}

No funding was received for this work.

\section{Author Contributions}

T.M.D. conceptualized the work. C.G.E. and T.M.D. wrote the initial manuscript draft, with substantial contributions to following versions by C.C.P., E.J.B., R.K.E., and D.G.-D. All authors approved the final manuscript as submitted and agree to be accountable for all aspects of the work.

References

Ann Nutr Metab 2020;76:371-374

1 Ofcom. Adults: Media Use and Attitudes Report 2019. London, UK: Ofcom; 2020 [cited 2020 Jul 1]. Available from: https://www.ofcom.org.uk/_data/assets/pdf_file/0021/ 149124/adults-media-use-and-attitudes-report.pdf

2 Ofcom. Children and Parents: Media Use and Attitudes Report 2019. London, UK: Ofcom; 2020 [cited 2020 Jul 1]. Available from: https:// www.ofcom.org.uk/_data/assets/pdf_ file/0023/190616/children-media-use-attitudes2019-report.pdf 
3 Quantcast. Twtich.tv traffic and demographic statistics by Quantcast. Quantcast; 2017 [cited 2006 Sep 20]. Available from: https://web.archive.org/web/20181218214411/.https://www. twitch.tv/year/2017/factsheet.jpg

4 Twitch. Twitch 2017 year in review. Twitch; 2018 [cited 2006 Sep 20]. Available from: https:// web.archive.org/web/20181218214411/. https:// www.twitch.tv/year/2017/factsheet.jpg

5 Pollack CC, Kim J, Emond JA, Brand J, Gilbert-Diamond D, Masterson TD. Prevalence and strategies of energy drink, soda, processed snack, candy and restaurant product marketing on the online streaming platform twitch. Public Health Nutr. 2020;23(15):2793-2803. https://doi.org/10.1017/s1368980020002128.
6 Federal Trade Commission. Guides concerning the use of endorsements and testimonials in advertising. Washington (DC); 2009.

7 Coates AE, Hardman CA, Halford JCG, Christiansen P, Boyland EJ. The effect of influencer marketing of food and a "protective" advertising disclosure on children's food intake. Pediatr Obes. 2019;14(10):1-9.

8 Thomas J, Peters C, Howell E, Robbins K. Social media and negative word of mouth: strategies for handing unexpecting comments. Atl Mark J. 2012;1(2):7.
9 Fox E. Nestle hit by Facebook 'anti-social' media surge. The Guardian; 2010. Available from: https://www.theguardian.com/sustainable-business/nestle-facebook.

10 Twitch. Twitch developer services agreement. Available from: https://www.twitch.tv/p/legal/developer-agreement/.

11 Cain RM. Embedded advertising on television: disclosure, deception, and free speech rights. J Public Policy Mark. 2011;30(2):22638.

12 Boyland E, Tatlow-Golden M. Exposure, power and impact of food marketing on children: evidence supports strong restrictions. Eur J Risk Regul. 2017;8(2):224-36. 